\title{
The Performance Reality of Youth Centers in Jordan From the Members' Perspective
}

\author{
Dr. Ibrahim Atallah AL-Ja'afreh (Corresponding author) \\ Assistant Professor in curriculum and teaching methods in physical education \\ AL-Hussein Bin Talal University-Jordan
}

Received: October 1, 2018 Accepted: October 25, 2018 Published: March October 31, 2018

doi:10.5296/ijld.v8i4.13724 URL: https://doi.org/10.5296/ijld.v8i4.13724

\begin{abstract}
This study aims to describe the reality of the performance of youth centers in Jordan from the perspective of their members. To achieve this aim, the researcher considers an analytical descriptive method involving the participants of members registered in the youth centers in Jordan. There were 550 participants recruited from a total of 40000 members available till the year $2018(13 \%)$. Within this design, the researcher develops and validate a 51-item instrument covering five aspects in this field: aims and planning, equipment and capabilities, socialization and volunteer, physical, sports and culture aspects. The results show that the performance of youth centers in all aspects is "Moderate". The results also reveal that there are statistically significant differences $(\alpha=0,05)$ between males and females in favor of females in the aspects of capabilities, equipment and culture. The study recommends governmental financial funding and supporting for these youth centers in the Ministry of Youth and Sport, so that they can achieve their aims. It also recommends providing these centers with the necessary equipment with incentives to activate members' role in developing the annual plans for these centers.
\end{abstract}

Keywords: Youth centers' performance, centers' members, reality of youth centers

\section{Introduction}

Youths are considered the future of any society which makes them the highest priority of this society. No society can exist in the civilized world without developing and caring for youths. Developing and caring for youths is the source of power for any government to build the future of the country as they can make a change and build the country and society (Abdul-Munim, 2011). It has been argued that caring for youths is professional, organized, and protective services with curing nature aiming to help them achieve their goals, which were derived from their society (Abdul-Salam \& Taha, 1991). 
With the modern technology and variation in knowledge resources, youth are now a power which cannot be ignored and is characterized by high energy and ability in creativity and critical thinking. Further, youths' thinking cannot be only restricted by what they acquire in their academic and social institutions but also their ability to judge ideas and influence the society. Therefore, countries which are concerned with youth programs have been constructing institutions that care for youths and organize their affairs and issues which help them participate in making decisions and working for their societies. It was clear from this argument that youth centers have an important role in accelerating the wheel of social affiliation of youth as well as their self-confidence and social relationships (Harahsheh \& Tuhaimir, 2011). This also indicates that activities provided by youth centers may have an important role to protect these youths from any behavioral disturbances (Hijazeen, 2013).

With the evolution and acceleration of events and the human integration in numeric life, building strategic plans of educational organizations to prepare youths for society became unavoidable. These strategic plans would be able to protect educational institutes as well as protect the country values and culture. Youth centers with these plans would be more efficient and able to update their plans according to youth preferences and developmental needs especially youth who visit these centers regularly.

Youth institutions are social and educational organizations which work on increasing youth awareness and investing their energy and capabilities through immersing them and participating in environmental and service programs planned by the youth centers (Mabrook \& Al-Tahami, 2006). These organizations belong to the Ministry of Youth and Sports which take its objectives from the vision of the Ministry. They promise to prepare future generations of athletes physically, mentally, psychologically, and socially. The organizations provide these athletes with sufficient knowledge and skills which enable them to fill their role in their society in a positive way (Al-Odat, 2005). Thus, these centers were considered one of the main guidelines in the country through which it supports youth in their centers with age of 12-18 for males and 12-24 for females. Within these centers, youth were involved in a variety of programs and activities prepared in these centers. These programs would help them acquire knowledge and skills that may influence their concepts and trends toward achieving the objectives of the Ministry of Youth and Sport in Jordan.

\subsection{The Significance of the Study}

The Jordanian Government represented by the Ministry of Youth is concerned with putting frameworks of caring for Jordanian youths. The Annual plans of youth centers in Jordan are reviewed regularly, with technical and financial fund provided to meet prompting needs of this group in the society. This review also helps to build up and update guidelines of the Ministry of Youth to suit these needs. The current study was developed to show the extent to which objectives were really achieved by youth centers. The study will also shed light on the performance of youth centers and their programs and how these programs satisfy and meet the individual needs and desires of youth. The importance of this study lies in its ability to uncover hidden abilities of youth as well as activities provided by centers to be addressed in this study. Therefore, the study is expected to provide a clear and comprehensive vision and image for decision makers in the Ministry of Youth to enable them to evaluate the extent to 
which objectives were achieved by youth centers. In parallel, this will also show strength and weakness strategies of these centers and help to build new and more focused strategies to fill any gap in achieving the aims of youth centers in Jordan.

\subsection{The Problem of the Study}

According to the literature review and the field experience of the researcher, it was shown that youth centers in Jordan were initiated since the 1960s with a purpose to develop a new generation of youth that belongs to its home country. These centers carry an important role to acquire youth values, attitudes and experiences which support their belonging to their home country and prepare them for the future and upcoming needs and requirements of their lives through programs and activities provided for youth in their centers for the age of 12-18 years and would be extended to 24 for females.

Youth centers are considered the frame through which the government achieves its goals and supports this age group in Jordan. Youth centers account for about 280 centers (male and female centers) distributed around all regions in the country (governorates, villages, rural areas, and countryside's). However, these centers do not follow organized or focused plans and programs, and consequently may not be able to achieve or apply these plans properly. Within these centers, coordinators and supervisors set the plans for different programs and activities to help youths build up their personality in all aspects focusing on mental, athletic, cultural, volunteer, social, and environmental aspects. This may aggregate the problem and make it more complicated where youths practice their plans and activities according to the supervisors of youth centers plans. A previous study by (Al-Odat, 2005) showed that the staff of these centers suffered from weakness which returns with negative results and feedbacks. Based on this argument, it was important to study the state of youth centers in Jordan from the perspective of their members. Thus, this study attempts to answer the following questions:

a) How is the performance of youth centers in Jordan from the perspective of their members?

b) Are there any significant differences in the performance of youth centers regarding the gender variable in Jordan?

\subsection{Objectives of the Study}

a) To know the current performance state of youth centers in Jordan according to the Ministry of Youth and Sports.

b) To recognize how performance state of youth centers and their services would differ according to gender variable.

\subsection{Definitions of Terms}

Youth center: youth body that is built up and developed by the Ministry of Youth and Sport with the budget is assigned for its activities. All those who work in this center are government employees.

Members of youth centers: the registered youth members with age between 12-18 years who visit these centers regularly and get benefit from services in these centers. 
Youth programs: a mixture of activities, relationships, interactions, and experiences to which youth are exposed to and help them in all life aspects.

Youth activities: all that members do in the youth center and provide them with new experiences.

\section{Literature Review}

The literature review of this study starts with discussing the importance of youth groups, their centers and all parties concerned with supporting them through specific programs. Caring for and supporting this group in Jordan went through several stages since the establishment of the Emirate (Jordan) in 1921:

a) Stage of nonintentional and spontaneous efforts which depends on popular and volunteer activities which were planned and performed by some institutions such as social and sports centers as well as charities.

b) Stage of unprogrammed youth care which was used to enrolling youth care with unrelated organizations, for example, the Ministry of Development and so on. Within this stage, a more specialized organization (Ministry of Youth, 1987) appeared and took the lead to care for Youth issues and organize their activities.

c) The third stage is the important stage in youth work and caring for youth as the law of youth care organization in Jordan has been issued in 1968. In this stage, the organization was developed and recognized as the only body responsible for creating and developing facilities, sports clubs, and youth centers in Jordan.

d) The fourth stage was the stage of developing the Ministry of Culture and Youth 1976 which became the legal extension to the youth care organization. Within this stage, the youth care issue was further disclosed and brought to the existence through creating more youth sports clubs. However, the Ministry of Culture and Youth has been moved to and merged with another discipline for a couple of years and was reinstated in 1984. Since then, the law of youth care has been re-activated with new updated regulations and instructions for youth care programs in Jordan.

e) In stage five, the Ministry of Youth was separated from the Olympic Committee because it was cancelled and replaced with the Youth Supreme Council in 2001. At the time, the law of the Council (No.66) was issued with giving this council the authority and the responsibility to raising a generation of youth who are adhered to his faith, belong to his home country, King and Arabism and respecting the constitution and the law in this country. Further, the council has an important role in organizing youth energies and consolidation of group work and volunteerism to actively participate in comprehensive national development; culturally, socially and economically. Furthermore, recreating sport was also a priority for this council with the purpose of developing the physical fitness, self-refinement, and achieving balanced growth for youth. All this was expected to provide a golden opportunity for youths to develop their talents and abilities. In addition to respecting the opposite opinion within a logical framework of freedom and responsibility. However, this framework may not be appropriately 
activated as youth welfare Act is being cancelled sometimes and referred to belong to the Ministry of Youth other times repeatedly.

Caring for youth is considered as curing profession that aims to help individuals and groups to rehabilitate and improve their social, psychological and mental abilities to match their society objectives and participate in building and protecting this society (Abdul Salam \& Taha, 1991). Two main objectives were set to be achieved by the organization of youth caring:

a) Preparing youth and providing them with the right social abilities and provide the available resources to achieve balanced growth in all aspects; mental, social, physical and psychological.

b) Directing all youth distinguished and creative abilities toward activating their role in permanent developmental fields to improve and bring up the society level in all fields. This will open the door for youth to take part in all life aspects; economic, political, and social.

(Al-Odat, 2005) reported some activities that were provided by youth centers such as cultural activities. Those activities present workshops, lectures, and social activities applied by members of youth centers, such as painting roads and platforms and cleaning mosques, cemeteries and schools. In addition, technical activities are also included through playing and painting, sculpture and plastic art and the sports activities that included applying a variety of games and sports (personal and groups) aiming to invest the free time and acquire additional skills, fitness and strength.

Moreover, (Al-Soub \& Imran, 2017) has approached this in his study that aimed to identify the role of youth centers in spreading the culture of sports and health in the light of the nationalist strategy for the youth in Karak governorate, from the perspective of members of those centers. The researcher used a qualitative approach for its effectiveness in this type of study as the target population group consisted of 590 members of which 139 were selected randomly. The results showed that the youth centers' contribution to spreading this culture was intermediary and the researcher recommended that there be more resources and methods to attract more members to those centers.

(Khadr et al., 2016) in a study aimed to determine the extent to which members in youth centers would participate in activities to protect the countryside. The study also explored the barriers to participate as well as their suggestions to increase this participation. This study was conducted in Sohaj city in Egypt where 260 members were selected from six youth centers representing three central areas in the city to take part in the study. The study found that participation rate was low with the most common causes were lack of resources to increase awareness on the risk of and how to deal with environmental pollution, lack of suitable places for educative sessions on how to protect the environment, and the lack of time as members were restricted to sports activities. All these were also accompanied with unclear objectives with no desire for renewal which amplified the problem. The participants in the study suggested offering resources with training sessions to increase awareness of the responsible people in the youth centers on the importance of environment protection. They also valued the appropriateness of training sessions with members' needs and time to allow them to increase their participation in programmed activities in their centers. 
(Hijazin, 2013) in his study aimed to know the role of youth activities in behavioral protection from the perspective of members and supervisors in youth centers in Jordan. The study distributed a survey to a purposive sample of 600 members and 133 supervisors from governorates in the south of Jordan. The study reported that activities delivered by youth centers were necessary and have an important role in behavioral protection. One of the main recommendations of the study was to use cultural and sports challenges and incentives as a mean to attract youth to youth centers.

Another study by (Al-Soub, 2013) highlighted the importance of activities and programs of the Supreme Council of Youth in developing the managerial skills in members of youth centers in Jordan. This study approached 400 participants from members in youth centers in Jordan for their perspective on these programs and activities. A quantitative survey was used in this study with six factors; communication skills, problem solving, decision making, administrative skills, knowledge and technical skills. The study showed an important role of activities and programs in developing managerial skills with a significant difference was found between males and females with males achieved higher scores $(p=0.03)$. One of the main recommendations of the study was to increase the number of female employees holding a higher degree education with Bachelor is the minimum.

A study was carried out at Al-Khartoum State in Sudan in 2011, which aimed to identify the national role through measuring to which extent the goals of youth centers have been accomplished. The study used a qualitative questionnaire to tackle five different areas (social, exterior relations, culture and media, education and planning and finally training). And the results of this study indicated that the youth were attending youth centers daily to participate in multiple activities, and it is worthy of noting that people attending youth centers originate from outer city areas. The researcher has pointed out the importance of providing such centers with psychological specialists (therapists).

(Abdul-Munim, 2011) approached the current state of youth centers from a perspective of how the centers have achieved the goals that they were created to achieve and what obstacles that affect youth center's performance. The researcher used took a qualitative approach in which she used 228 centers as a random sample, and some of the more prominent findings were that the goals of the youth centers were very much in line with state's strategies in the field of public service. One of the greatest obstacles and negatives of those strategies is that they set by the Egyptian national higher council.

Moreover, (Bandaq, 2011) carried out a study to explore the role taken by youth centers in developing a sense of nationalism in the Egyptian woman. The population of the study took into account members of the Mahalah youth center in the Arab Republic of Egypt, and on that basis, a sample of 100 members was chosen randomly. The researcher used a qualitative survey in this study that covered the issue from four dimensions that were: nationalistic values, rights, participation and responsibilities. The study concluded that women participants reflected a high response in all four dimensions.

In a similar study, (Harahsheh \& Tuhaimir, 2011) took a closer look at the role of youth centers in creating a sense of social nationalism in a sample from the members of youth 
centers in Jordan. The researcher considered the inputs of different parts of the centers made including (inputs from the centers to personal development, inputs made by programs and activities, inputs made by the centers' superintendents). The study population consisted of 93 centers and a sample of 393 members was randomly chosen. The most important conclusion the researcher came to be that youth centers played a big part in creating the social nationalism, and a slightly smaller part in developing self-confidence and social relationships. The researcher recommended that youth centers must be further supported.

Additionally, (Brennan et al., 2007) investigated the factors affecting young people's engagement in youth activities. The researchers used a qualitative approach and interviews as a measure and 418 people were taken as a random sample in the State of Florida in the USA. It was found that the youth engagement in activities was closely tied to their desire to improve their skills and achieve what they aspire to be in the future. Besides, the researcher recommended that such activities be supported and attract youth to take part in those activities leaving space for them to express their interests in the activities.

(Al-Odat, 2005) aimed to find a suggested model for youth, considering the evaluation of current times from the viewpoint of supervisors and members in youth centers. The sample consisted of 118 supervisors 380 members of the managing body and the researcher used a survey as an instrument to measure the responses that covered 8 areas (facilities and equipment, management, programs and activities, cultural programs, social activities, artistic activities, information technology and sports activities). The most notable findings were that the facilities and equipment, informational technology and sports activities were at an intermediate level while the management was at a low level in the evaluation of the performance of youth centers. The researcher had recommended setting up new halls and facilities specifically for activities in the youth centers.

(Kathrine, 2005) explored the physical changes in teenagers in schools along with changes that occur in their interactions and communication with others. (Daood \& Barham, 1996) aimed to explore the status of the problems facing youth centers in Palestinian refugee camps from the perspective of their management. The study covers several fields, two of which are the financial and social fields. The sample included 97 moderators, who represented the original population and were given surveys to measure their responses. It was found that there were no differences in the responses on the financial level, but differences were seen in the social part of the survey between different members of the sample. The main recommendation of the study is to further fund youth centers through the UNRWA and the ministry of youth and sports.

(Daghash \& Abdallah, 1996) investigated the importance of finding the required managerial competencies in moderators for youth centers and their application of those skills from the perspective of members. The study included 20 moderators and 511 members that were randomly selected. And the researcher used a survey as an instrument to measure responses of the sample. The survey considered some factors including personal, psychological, professional, humanitarian relationships, the capability of working with youth. And results showed that moderators had a high level of managerial competence. 


\section{Macrothink}

International Journal of Learning and Development

ISSN 2164-4063 2018, Vol. 8, No. 4

\section{Comments on the Previous Studies}

Having reviewed the previous studies concerning the present study, the researcher has made use of the methodology used for that type of research including the methods of selecting the samples, choosing the response measuring instruments, the use of statistical methods used as well as the recommendations that resulted from the studies. Most of the studies agreed on taking a qualitative approach, taking the samples randomly and used a survey as a method of collecting responses from the selected sample. The most prominent study of those is (Al-Soub, 2013) which shed light on the leadership skills of youth center members in Jordan. The studied sample consisted of 400 members. A survey was used which covered 6 main aspects (communication skills, problem solving, professional, cognitive and participation skills) in decision making, whereas (Al-Odat, 2005) created a model for youth centers by studying the current state of centers. (Abdul-Munim, 2011) aimed to find the role of youth centers in developing the value of nationalism in the Egyptian woman, and the population of the study consisted of members of Al-Mahala youth center in the Arab republic of Egypt. (Daood \& Barham, 1996) explored the problems facing youth centers in refugee camps from the perspective of their moderators. (Hijazeen, 2013) studied the role of youth centers in preventing behavioral deviation from the view of members and moderators of youth centers in Jordan-southern governorates. (Daghash \& Abdallah, 1996) highlighted the managerial competencies needed in moderators and how much they are practiced from the view of members, where the sample consisted of youth center moderators. This study differs from the other studies by using a different sample and it focused on new aspects within youth programs in addition to studying the current state and performance of those centers.

\section{Methods}

The researcher used a qualitative approach as it is the most suitable for this type of study.

\subsection{Participants}

The population being studied consists of all the registered members of youth centers which until 2018 were recorded at 40000 members, and a sample of 13\% of active members in center activities with a total of 550 members from youth centers in five southern governorates that are Aqaba, Karak, Ma'an, Tafilah and Petra.

Table 1. Sample distribution based on gender

\begin{tabular}{lll}
\hline Gender & Number & Percentage \\
\hline Male & 244 & $44.4 \%$ \\
Female & 306 & $55.6 \%$ \\
Total & 550 & $100 \%$ \\
\hline
\end{tabular}




\subsection{Materials}

The researcher developed an instrument to carry out this study, and it is a scale that consists of five pillars. Those pillars are plans and goals, facilities and equipment, social and voluntary work, as well as cultural and sports activities. These pillars were spread over 52 items to measure their trends. This instrument was presented to a group of 10 faculty members that are academically specialized and to 5 of the youth leaderships that work with youth in the ministry of youth and sports in Jordan, to make sure of the validity of the content. A few items were modified and 3 were replaced based on the feedback provided by the moderators and $75 \%$ of them agreed on the suggested changes. Thereby, the instrument was finally put into application in its final form consisting of 51 items on a test sample from outside the intended population, where the Cronbach alpha equation was applied and has a reliability of 0.81 , which is a relatively high value to carry out this type of study.

Responses from the sample were assorted based on the opinions of moderators into 3 levels to determine the level of performance of the youth centers, as shown in Table 2.

Table 2. Assortment of the point averages

\begin{tabular}{ll}
\hline Level & Average categories \\
\hline High & 3.66 or more \\
Intermediate & $2.34-3.66$ \\
Low & 2.34 or less \\
\hline
\end{tabular}

\section{Result and Discussion}

To answer the first question, which is: How is the performance of youth centers in Jordan from the perspective of their members? Scores and means for members' responses have been calculated for each individual item of the questionnaire according to fields and categories within its items. This was shown in Tables 3, 4, 5, 6, 7 and 8 .

Table 3. Means and standard deviations for participants' responses in all fields

\begin{tabular}{llllll}
\hline Field no. & Field label & Mean & SD & Rank & Degree \\
\hline 1 & Aims and planning & 3.1940 & 0.30188 & 3 & Medium \\
2 & Equipment and capabilities & 3.3620 & 0.38344 & 2 & Medium \\
3 & Socialization and volunteer & 3.1940 & 0.33581 & 3 & Medium \\
4 & physical and sport & 3.4980 & 0.32060 & 1 & Medium \\
5 & Culture & 3.0782 & 0.41259 & 5 & Medium \\
6 & Total & 3.2616 & 0.22567 & & Medium \\
\hline
\end{tabular}

It was clear from Table 3 that degrees in all fields were "Medium" with moderate means 
which indicates the weakness in centers' performance in these fields. The researcher would correlate this with the absence of objective of centers and organized plans, in addition to recurrence and duplication of annual plans. Regarding the "equipment and capabilities" field, the centers lack the minimum level of equipment and capabilities to work properly, since the budget for the activities that included in the plan does not cover these activities expenses, which may also influence other fields such as socialization and volunteer, physical and sport, and culture.

Table 4. Means and standard deviation in items of "aims and planning"

\begin{tabular}{|c|c|c|c|c|c|}
\hline $\begin{array}{l}\text { Item } \\
\text { no. }\end{array}$ & Statement & Mean & SD & Rank & Degree \\
\hline 1 & There were clear objectives for centers' annual plans & 4.18 & 0.460 & 4 & High \\
\hline 2 & $\begin{array}{l}\text { I directly participate in setting the objectives of annual plans with } \\
\text { centers moderators }\end{array}$ & 1.80 & 0.601 & 8 & Low \\
\hline 3 & The annual plan was recognized as flexible & 2.02 & 0.648 & 7 & Low \\
\hline 4 & The annual plan of the center includes all required activities & 1.56 & 0.669 & 10 & Low \\
\hline 5 & $\begin{array}{l}\text { The objectives of the center's annual plan consider members' } \\
\text { needs }\end{array}$ & 4.36 & 0.719 & 2 & High \\
\hline 6 & It is possible to achieve the pre-determined objectives in the plan & 1.66 & 0.816 & 9 & Low \\
\hline 7 & $\begin{array}{l}\text { Objectives of the center's annual plan are clear and } \\
\text { comprehensive }\end{array}$ & 4.18 & 0.793 & 4 & High \\
\hline 8 & Activities in the annual plan were being implemented accurately & 4.44 & 0.779 & 1 & High \\
\hline 9 & Objectives in the center's annual plan achieve the center's goal & 3.42 & 1.359 & 6 & Medium \\
\hline 10 & Objectives in the center's annual plan motivate the creators & 4.30 & 0.671 & 3 & High \\
\hline
\end{tabular}

Table 4 shows that items on the annual plans and their objectives came with "High" and "Low" scores with highest scores were observed on the item "Activities in the annual plan were being implemented accurately" (Mean=4.44, $\mathrm{SD}=0.779)$ and "Low" score was on the item "The annual plan of the center includes all required activities" (Mean=1.56, SD=0.669). These scores were an indicator, from the researcher's perspective, of activities performance by members in the centers, through guidelines of the annual plan within the available possibilities. Further, national and religious occasions would be considered in setting such plans and activities with incentive plans would also be provided through the Ministry of Education.

The only item with "Medium" score was "Objectives in the center's annual plan achieve the center's goal" (Mean=3.42, $\mathrm{SD}=1.359$ ) which may show that centers would not achieve their objectives appropriately. The researcher here explained this by limited and unfocused objectives, which consequently complicate the process of regular evaluation.

For those items with "Low" scores in youth centers performance as presented in the table above, the item "The annual plan of the center includes all required activities" was the lowest 


\section{Macrothink}

one with Mean 1.56, SD 0.669 followed by "I directly participate in setting the objectives of annual plans with centers moderators" (Mean 1.80, SD 0.601). The researcher interpreted these low scores with members' feeling that the plan and objectives would not meet their needs and requirements because moderators and supervisors were not aware of these needs within the age of (12-18 years). This was also accompanied by the specialties of moderators which mainly fell within sports fields which clearly shows the need of centers for more specialized people who can deal with a variety of issues; psychological, guidance, and social service. These fields would be more interactive and efficient in dealing with members and managing programs within the center. This finding was consistent with the study of (Al-Odat, 2005) regarding the lack of equipment and possibilities and (Abdul-Munim, 2011) about pairing the center's objectives with the strategic objectives for the country Jordan. However, different findings were reported in (Abdul-Munim, 2011) and (Hijazeen, 2013) where nationalism values for Egyptian woman in youth centers were high which was explained in other studies study by the difference in sample, environment and setting of the study. In (Hijazeen, 2013), researchers showed that the nature of study objectives differed in studying the deviated behavor which might not be comparable with those in the current study.

Table 5. Means and standard deviation in items of "equipment and capabilities"

\begin{tabular}{|c|c|c|c|c|c|}
\hline $\begin{array}{l}\text { Item } \\
\text { no. }\end{array}$ & Statement & Mean & SD & Rank & Degree \\
\hline 11 & $\begin{array}{l}\text { The financial allocations are sufficient to implement programs and } \\
\text { activities in the annual plan for the center }\end{array}$ & 2.22 & 0.460 & 9 & Low \\
\hline 12 & $\begin{array}{l}\text { M center can accommodate programs and activities being } \\
\text { implemented }\end{array}$ & 1.80 & 0.825 & 10 & Low \\
\hline 13 & Multi-functional venues are available for activities & 4.18 & 0.713 & 3 & High \\
\hline 14 & $\begin{array}{l}\text { Moderators provide the right atmosphere for members to practice } \\
\text { activities }\end{array}$ & 4.56 & 0.497 & 1 & High \\
\hline 15 & $\begin{array}{l}\text { Moderators provide advice and guidance for members according } \\
\text { to their age }\end{array}$ & 4.36 & 0.976 & 2 & High \\
\hline 16 & The number of moderators is adequate in the center & 3.14 & 1.430 & 6 & Medium \\
\hline 17 & An equipped lounge is available in the center for physical fitness & 3.14 & 1.416 & 6 & Medium \\
\hline 18 & $\begin{array}{l}\text { Moderators who are specialized in all activities are available in the } \\
\text { center }\end{array}$ & 3.86 & 1.234 & 4 & High \\
\hline 19 & $\begin{array}{l}\text { Instrument necessary for different activities are available in the } \\
\text { center }\end{array}$ & 3.12 & 1.382 & 8 & Medium \\
\hline 20 & $\begin{array}{l}\text { Centre equipment is valid and available always to practice } \\
\text { different activities }\end{array}$ & 3.24 & 1.409 & 5 & Medium \\
\hline
\end{tabular}

It is clear from Table 5 that low means were observed for two items related to "equipment and capabilities" in youth centers. For example, for the item "My center can accommodate programs and activities being implemented", (Mean=1.8, $\mathrm{SD}=0.825)$, the lowest mean recorded. The other item with low mean was "The financial allocations are sufficient to 
implement programs and activities in the annual plan for the center", (Mean=2.22, $\mathrm{SD}=0.460)$.

The researcher has correlated the low scores to lack of financial resources as well as the insufficient financial allocations within youth centers budget, which would end up with limitation in activities provided by these centers. It was clear that the financial deficit in the country was common in all other organizations, where financial allocations would be inadequate. In addition to that, moderators and administrators in youth centers depend only on what the Ministry of Youth provided from the financial fund, without any donations from the surrounded society for some activities in the centers. This was interpreted by the researcher by either an inactive collaboration between centers with the surrounding community or the unclear role of centers with inexperienced staff, in how to market their centers outside their community. These findings were supported by studies by (Al-Odat, 2005) and (Abdul-Munim, 2011) regarding the insufficient resources and equipment in youth centers.

Four items obtained "High" scores by the participants; "Moderators provide the right atmosphere for members to practice activities" (Mean=4.56, $\mathrm{SD}=0.497$ ); "Moderators provide advice and guidance for members according to their age" (Mean=4.36, $\mathrm{SD}=0.476$ ); "Multi-functional venues are available for activities" (Mean=4.18, SD=0.713); and "Moderators who are specialized in all activities are available in the center" (Mean=3.86, $\mathrm{SD}=1.234)$. These responses showed that members in the centers were committed with implementing their designed plans, which was also followed by managers in the Ministry of Youth. The researcher also believed that advices and guidance provided by moderators were on activities themselves rather than an age issue.

Participants' responses on the item "Moderators provide the right atmosphere for members to practice activities" were recorded as highest, Mean=4.56, $\mathrm{SD}=0.497$ ). These responses implied high abilities of moderators to provide advice and supervision for members. There were four responses with "Medium" scores; "The number of moderators is adequate in the center" (Mean=3.14, SD=1.430); "An equipped lounge is available in the center for physical fitness" (Mean=3.14, $\mathrm{SD}=1.416$ ); "Instrument necessary for different activities are available in the center" (Mean=3.12, $\mathrm{SD}=1.382$ ); "Centre equipment is valid and available always to practice different activities" (Mean=3.24, $\mathrm{SD}=1.409$ ). From the researcher perspective, these responses showed that the number of members would be high in the centers which might be sufficient, but this might disturb their work since specialization was not considered in the recruitment process. In addition to the scarce of sports halls, except few of those halls that were well equipped by the royal funds. 
Table 6. Mean of scores and standard deviations for each item in volunteer social field

\begin{tabular}{|c|c|c|c|c|c|}
\hline $\begin{array}{l}\text { Item } \\
\text { no. }\end{array}$ & Statement & Mean & SD & Rank & Degree \\
\hline 21 & The center organizes the voluntary works for the member & 2.92 & 1.427 & 7 & Medium \\
\hline 22 & I feel happy with voluntary work in the center & 3.24 & 1.423 & 3 & Medium \\
\hline 23 & Voluntary work strengthens my belonging to the center & 2.54 & 1.460 & 9 & Medium \\
\hline 24 & $\begin{array}{l}\text { I enjoy participating in voluntary work which is organized by the } \\
\text { center }\end{array}$ & 2.46 & 1.331 & 10 & Medium \\
\hline 25 & I like to practice voluntary work with my colleagues in the center & 4.14 & 1.078 & 2 & High \\
\hline 26 & $\begin{array}{l}\text { Practicing voluntary activities which are organized by the center } \\
\text { makes me feel active }\end{array}$ & 3.22 & 1.239 & 4 & Medium \\
\hline 27 & $\begin{array}{l}\text { Practicing voluntary activity in the center makes me feel } \\
\text { self-satisfied }\end{array}$ & 2.84 & 1.392 & 8 & Medium \\
\hline 28 & I like to practice voluntary work with my friends in the center & 3.00 & 1.282 & 6 & Medium \\
\hline 29 & Voluntary works in the center help me to accept others & 3.14 & 1.416 & 5 & Medium \\
\hline 30 & $\begin{array}{l}\text { Voluntary work organized by the center increase my reaction with } \\
\text { others }\end{array}$ & 4.44 & 0.779 & 1 & High \\
\hline
\end{tabular}

Table 6 shows that the highest scores (High) were on two items; "I like to practice voluntary work with my colleagues in the center" (Mean=4.14, SD=1.078)" and "Voluntary work organized by the center increase my reaction with others" (Mean=4.44, SD=0.779). All other items were scored "Medium" with least scored was "I enjoy participating in voluntary work which is organized by the center" (Mean=2.46, $\mathrm{SD}=1.331$ ) and highest was "I feel happy with voluntary work in the center" (Mean=3.24, $\mathrm{SD}=1.423$ ).

It's clearly evident that members in youth centers have the ability to work voluntarily, and they recognize that this work may empower their reaction with others which has also a positive impact on building their personality.

Table 7. Mean and SD achieved by participants on the sports field items

\begin{tabular}{llllll}
\hline $\begin{array}{l}\text { Item } \\
\text { no. }\end{array}$ & Statement & Mean & SD & Rank & Degree \\
\hline 31 & $\begin{array}{l}\text { The center organizes sports activities that develop managerial } \\
\text { characteristics }\end{array}$ & 3.42 & 1.359 & 6 & Medium \\
32 & The center conducts different sports activities & 4.30 & 0.671 & 3 & High \\
33 & $\begin{array}{l}\text { The center conducts sports activities that develop my physical } \\
\text { fitness }\end{array}$ & 2.22 & 0.460 & 9 & Low \\
34 & The center organizes sports activities beneficial for health & 1.80 & 0.825 & 10 & Low \\
35 & The center offers trainers for sports activities & 4.18 & 0.713 & 4 & High \\
36 & The center conducts entertainment sports & 4.56 & 0.497 & 1 & High \\
\hline
\end{tabular}


37 The center organizes sports activities for weight loss

38
The center organizes sports activities that develop muscular power for members

The center organizes sports tournaments for all games

I receive sports training on individual games in the center
4.36

0.976

$3.14 \quad 1.430 \quad 7$

$3.14 \quad 1.416 \quad 7$

$3.86 \quad 1.234 \quad 5$
High

Medium

Medium

High

It is clear in Table 7 that participants' responses on the performance of youth centers were uneven with 5 items "high", 3 "Medium", and 2 "Low". The highest scores were observed on the item "The center conducts entertainment sports" (Mean=4.56, SD=0.497) and the lowest was on the item "The center conducts sports activities that develop my physical fitness" (Mean=2.22 SD=0.460).

The researcher explained the medium and low degrees by the inability of the programs in their plans to meet the favors and needs of members. The annual plans were set for the centers without determining the aims of activities, which might further explain that members who work with youth in youth centers are not well prepared to deal with and help this group.

Table 8 . Mean and standard deviations achieved by participants on items of the culture field

\begin{tabular}{|c|c|c|c|c|c|}
\hline $\begin{array}{l}\text { Item } \\
\text { no. }\end{array}$ & Statement & Mean & SD & Rank & Degree \\
\hline 41 & The annual plan of the center includes many cultural activities & 3.12 & 1.382 & 6 & Medium \\
\hline 42 & The center arranges for lectures in religious occasions & 3.24 & 1.409 & 2 & Medium \\
\hline 43 & The center organizes parties in national occasions & 2.92 & 1.427 & 8 & Medium \\
\hline 44 & $\begin{array}{l}\text { The center organizes cultural competitions for members in all } \\
\text { fields }\end{array}$ & 3.24 & 1.423 & 2 & Medium \\
\hline 45 & The library of the center includes books that I like to read & 2.54 & 1.460 & 10 & Medium \\
\hline 46 & The center organizes parties in national occasions & 2.46 & 1.331 & 3 & Medium \\
\hline 47 & $\begin{array}{l}\text { The center organizes lectures to increase awareness of the } \\
\text { harmful effects of smoking }\end{array}$ & 4.14 & 1.078 & 1 & High \\
\hline 48 & $\begin{array}{l}\text { The center organizes lectures to increase awareness of the scourge } \\
\text { of drugs }\end{array}$ & 3.22 & 1.239 & 4 & Medium \\
\hline 49 & $\begin{array}{l}\text { The center organizes scientific and cultural trips to national } \\
\text { institutions }\end{array}$ & 2.84 & 1.392 & 9 & Medium \\
\hline 50 & The center organizes entertainment trips to tourist areas & 3.00 & 1.282 & 7 & Medium \\
\hline 51 & The center participates in cultural festivals & 3.14 & 1.416 & 5 & Medium \\
\hline
\end{tabular}

It is clear in Table 8 that the degree of participant agreement was "high" on the statement "The center organizes lectures to increase awareness of the harmful effects of smoking" with Mean was $4.14, \mathrm{SD}=1.078$. The rest of the items were "Medium" with the highest scores were obtained on the item "The center arranges for lectures in religious occasions" 


\section{Macrothink}

International Journal of Learning and Development

ISSN 2164-4063

2018, Vol. 8, No. 4

(Mean=3.24, $\mathrm{SD}=1.409)$ and lowest scores were on the item "The center organizes parties in national occasion" (Mean=2.46, $\mathrm{SD}=1.331)$.

These medium scores were associated with the incomplete role of youth centers which may be due to different factors, one of which was limited financial resources as well as the lack of specialized libraries for this age group. It can be said here that members in youth centers were originally school students who do not have sufficient experience to play an active role in all cultural activities, such as religious and national occasions. This may limit centers' active participation in these occasions, since members usually prefer kinetic activities over the cultural ones, meanwhile centers were not concerned with cultural competitions to encourage members to participate actively. The danger here lies in limited consolidation the concept of citizenship for members of youth centers.

To answer the second question: are there any significant differences in the performance of youth centers regarding the gender variable in Jordan? A t-test for independent samples was used to test the difference between means of males and females (Table 9).

Table 9. Means with t-test comparisons between males and females

\begin{tabular}{llllc}
\hline Statement & Gender & Mean & t-test & Sig. p \\
\hline Field of planning and objectives & Males & 3.1984 & 0.302 & 0.763 \\
& Females & 3.1905 & & \\
\hline Field of capabilities and equipment & Males & 3.2721 & $*_{-} 5.015$ & 0.000 \\
& Females & 3.4337 & & \\
\hline The social and voluntary Field & Males & 3.2037 & 0.604 & 0.546 \\
& Females & 3.1863 & & \\
\hline The sport Field & Males & 3.4689 & -1.909 & 0.057 \\
& Females & 3.5212 & & \\
\hline The culture field & Males & 3.0346 & $*-2.217$ & 0.027 \\
& Females & 3.1129 & & \\
\hline All fields & Males & 3.2316 & $*-2.798$ & 0.005 \\
& Females & 3.2855 & & \\
\hline
\end{tabular}

(* significant difference when $\mathrm{p} \leq 0.05$ )

There was significant difference in total scores between males and females $(\mathrm{t}=-2.798$, $\mathrm{p}=0.005)$. However, the significant difference between males and females was observed in only two fields; capabilities and equipment $(\mathrm{t}=-5.015, \mathrm{p}=0.000)$ for females and the culture field $(\mathrm{t}=-2.217, \mathrm{p}=0.027)$ also for females.

The researcher believed that these differences between the cultural field and the equipment field were due to specific privacy especially for those involved in the study, since the 
equipment and needs might differ with different regions in the country. Thus, these differences may be reasonable as the centers were limited to activities that may be funded by these centers. Further, these centers used to arrange with health organizations to conduct activities about women health which explains the differences in this field as significant for females.

\section{Recommendations}

Based on the results of the study, the following recommendations are suggested:

a) Upgrading the services provided by youth centers in Jordan in all fields in the study (aims and planning, equipment and capabilities, socialization and volunteer, physical and sport and culture).

b) Providing youth centers with the necessary equipment to apply their annual plans.

c) Giving the chance for members to participate in preparing the annual plans for these centers.

d) Giving the chance for members to announce, lead and conduct their activities to facilitate members' communication.

e) Launch programs and activities required by youth registered in these centers by the Ministry of Youth and Sport and watch the performance of youth centers.

f) Evaluate youth centers regularly by registered members in these centers.

g) Evaluate youth centers based on clear guidelines through achieving the desired objectives for which it was established.

h) Conduct research and studies in other fields in the way these centers work.

\section{References}

Abdul-Munim, E. (2011). The state of developed youth centers in Egypt and future vision to go up with managerial policies within quality parameters. Unpublished Master thesis. Helwan University, Egypt.

Abdul-Salam, T., \& Taha., M. (1991). Studies in recreation and youth centers. Dar Al-Maaref. Egypt.

Al-Odat., M. (2005). Setting a proposed framework for youth centers in Jordan within current state from the perspective of supervisors and members in youth centers. Unpublished Master thesis. University of Jordan, Jordan.

Al-Shehab, A., \& Al-Sawi., M. (2002). Field study of workers and members' perceptions in Youth centers about Educational role in Kuwait community. Educational magazine, 6(62).

Al-Soub, S., \& Imran, M. (2017). The role of youth centers in spreading sport and health culture in the light of national strategy for youth in Karak Governate from the perspective of members, Studies of education sciences, 44(3). Jordan.

Al-Soub., K. (2013). The role of programs in the Supreme Council of Youth in developing managerial skills of youth centers' members in Jordan. Unpublished Master thesis. Mutah 


\section{Macrothink}

International Journal of Learning and Development

ISSN 2164-4063 2018, Vol. 8, No. 4

University, Karak-Jordan.

Bandaq, T. (2011). Youth centers and the development of nationality value for Egyptian woman. Journal of studies in social service and human sciences, 30(5).

Brennan, M. A., Brennt, R. V., \& Baugh, E. (2007). Youth involvement in Community Development. Journal of Extension,45(4).

Daghash, S. \& Abdallah, J. (1996). Managerial competencies necessary for leaders in youth centers and its application by those leaders from the perspective of members. unpublished thesis. University of Jordan, Amman.

Daood., \& Barham, T. (1996). The state of problems against activities of youth centers in Palestinian refugee camps in West Bank from the perspective of managers. Unpublished master thesis. Najah National University, Nablus, Palestine.

Harahsheh, M. \& Tuhaimir, A. (2011). The role of youth centers in developing social belonging for a group of youth centers employees in Jordan. Unpublished master thesis. Yarmouk University, Jordan.

Hijazeen, Y. (2013). The youth activities in the protection from behavioral deviation from the perspective members and supervisors of Jordanian youth centers in South Region governorates. Unpublished Doctoral thesis. Mutah University, Jordan.

Kathrine, S., \& Castle. Management Groups for Middle School. The Bureau a T Risk, NCC of The New York State School Counselor Youth Association.

Khedr, F., Kandil, M., AlShaer, G., \& Abdul Hady, M. (2016). Participation of Youth Centers Members in Rural Environment Conservation in Sohag Governorate, Agric. Econom. and Social Sci,7(7), 729-732. Mansoura University.

Mabrouk, S., \& Al-Tuhami, A. (2006). Effectiveness of environmental organizational entrance in alleviation of negative environmental behavior for youth centers members. Journal of social and human sciences studies, 21(3), Social service college, Egypt.

Society Studies Centre. 2011. (SSC). The state of Youth centers in Khurtoom State.

The Ministry of Youth. (1987). The Youth Welfare Act and regulations issues by the Act. Amman-Jordan.

The Supreme Council of Youth. (2001). The law of Supreme Council of Youth and regulations issued by the council. Amman-Jordan.

\section{Copyright Disclaimer}

Copyright for this article is retained by the author(s), with first publication rights granted to the journal.

This is an open-access article distributed under the terms and conditions of the Creative Commons Attribution license (http://creativecommons.org/licenses/by/4.0/). 